\title{
A Clinical Trial Comparing BiVap (Richard Wolf囚) Saline Vaporization of The Prostate vs. TwisterTM Diode Laser System in The Treatment of Benign Prostatic Obstruction Between Prostate Volume 90 to $150 \mathrm{ml}$.
}

\author{
Ayhan Karaköse ${ }^{1}$ and Yasin Yitgin ${ }^{1}$ \\ ${ }^{1}$ Istinye University
}

February 27, 2021

\begin{abstract}
Introduction:To evaluate the efficacy, safety and postoperative outcomes of the BiVap saline vaporization and Twister Diode Laser systems with benign prostatic obstruction (BPO) in prostate volüm between 90-150 ml. Methods:In total, we included 131 patients treated with BiVap system $(n=68)$ and Twister system $(n=63)$. Postoperative complications including urinary tract infection, transient hematuria, severe dysuria and fever $>38^{\circ} \mathrm{C}$, urinary incontinence and urethral stricture were also noted. All patients were evaluated at the postoperative 1st, 3rd, 6th and 12th month and preoperative and postoperative values of IPSS score, QoL score, total PSA, IIEF 15, PVR, Qmax and Qave were compared. Statistical analyses were performed with SPSS version 18. A P-value $<0.05$ was considered significant. Results:Preoperative demographic characteristics were similar in the 2 groups. There was observed significant improvement for IPSS, Qmax, Qave, PVR, and QoL score by the postoperative first month compared to the preoperative values in both groups. Maximum improvement in the IPSS, Qmax, Qave, QoL score and PVR were achieved at postoperative $6,3,12,3$ and 12th months respectively in group 1 . In group 2 maximum improvement in the IPSS, Qmax, Qave, QoL score and PVR were achieved at postoperative 6, 3, 6, 6 and 12th months, respectively. There was no significant difference between the two groups in terms of IPSS, Qmax, Qave, QoL score, PSA, PVR, IIEF-EF and IIEF-OS during the 1 year follow-up period postoperatively. Conclusions:BiVap and Twister systems are safe, effective, and useful technique, which can be used in the surgical treatment of BPO between 90-150ml.
\end{abstract}

A Clinical Trial Comparing BiVap (Richard Wolf@) Saline Vaporization of The Prostate vs. Twister ${ }^{\text {TM }}$ Diode Laser System in The Treatment of Benign Prostatic Obstruction Between Prostate Volume 90 to $150 \mathrm{ml}$.

\section{Ayhan Karakose 1, Yasin Yitgin 1}

${ }_{1}$ Istinye Universtiy Faculty of Medicine, Depatment of Urology, Esenyurt/Istanbul, Turkey

Keywords : Vaporization; Prostatic obstruction; BiVap; Twister

Ayhan Karakose, Prof. Dr.

Phone: +90 212 9794000/4458

Adress: Istinye Universtiy Faculty of Medicine, Depatment of Urology, Esenyurt/Istanbul, Turkey e-mail:ayhan.karakose@isu.edu.tr

Facsimile Number: +902124813688

Yasin Yitgin, M.D. (Corresponding author) 
Phone: +90 212 9794000/1009

Adress: Istinye Universtiy Faculty of Medicine, Depatment of Urology, Esenyurt/Istanbul, Turkey

e-mail:yasinyitgin@hotmail.com

Facsimile Number: +902124813688

Corresponding author: Yasin Yitgin

Competing interests: None

\section{Hosted file}

manuscript.pdf available at https://authorea.com/users/398521/articles/511114-a-clinicaltrial-comparing-bivap-richard-wolf-saline-vaporization-of-the-prostate-vs-twistertmdiode-laser-system-in-the-treatment-of-benign-prostatic-obstruction-between-prostatevolume-90-to-150-ml

\section{Hosted file}

Table 1.pdf available at https://authorea.com/users/398521/articles/511114-a-clinical-trialcomparing-bivap-richard-wolf-saline-vaporization-of-the-prostate-vs-twistertm-diodelaser-system-in-the-treatment-of-benign-prostatic-obstruction-between-prostate-volume90-to-150-ml

\section{Hosted file}

Table 2.pdf available at https://authorea.com/users/398521/articles/511114-a-clinical-trialcomparing-bivap-richard-wolf-saline-vaporization-of-the-prostate-vs-twistertm-diodelaser-system-in-the-treatment-of-benign-prostatic-obstruction-between-prostate-volume90-to-150-ml

\section{Hosted file}

Table 3.pdf available at https://authorea.com/users/398521/articles/511114-a-clinical-trialcomparing-bivap-richard-wolf-saline-vaporization-of-the-prostate-vs-twistertm-diodelaser-system-in-the-treatment-of-benign-prostatic-obstruction-between-prostate-volume90-to-150-ml

\section{Hosted file}

Figure 1.pdf available at https://authorea.com/users/398521/articles/511114-a-clinicaltrial-comparing-bivap-richard-wolf-saline-vaporization-of-the-prostate-vs-twistertmdiode-laser-system-in-the-treatment-of-benign-prostatic-obstruction-between-prostatevolume-90-to-150-ml 